\title{
Vida de Estudante Durante a Pandemia: Isolamento Social, Ensino Remoto e Satisfação com a Vida
}

\author{
Student Life During Pandemic: Social Isolation, \\ Remote Education and Life Satisfaction
}

Kelmara Mendes Vieira ${ }^{{ }^{*}}$ Gabrielle Fagundes Postiglioni ${ }^{1}$ Géderson Donaduzzi ${ }^{1}$ Caroline dos Santos Porto ${ }^{1}$ Leander Luiz Klein ${ }^{1}$

1 Universidade Federal de Santa Maria, Avenida Roraima, número 1000, prédio 74C sala 4212, Santa Maria - Rio Grande do Sul - Brasil. *kelmara@terra.com.br

\section{(c) (i)}

Recebido 17/08/2020 Aceito 21/09/2020 Publicado 23/09/2020

\section{Resumo}

A pandemia de COVID-19 atingiu muitos países em 2020, incluindo o Brasil, que adotou diversas medidas para combater o vírus, interferindo assim na vida da sociedade, especialmente com a exigência do isolamento social. Para manter as atividades letivas, a Universidade Federal de Santa Maria iniciou o Regime de Exercícios Domiciliares Especiais, para os cursos presenciais. Esse estudo investigou o isolamento social, a adoção do ensino remoto e a mudança na satisfação com a vida desses estudantes. Para isso adotou-se uma survey online, cujas respostas foram analisadas com a estatística descritiva, análise fatorial exploratória e regressão linear múltipla. Os resultados indicam que a maioria dos estudantes está praticando o isolamento e saindo de casa apenas para a compra de produtos essenciais. Nesse processo de "ficar em casa" os estudantes percebem queda na produtividade, alterações de humor e sentimentos de angústia e ansiedade. A satisfação com a vida hoje é menor quando comparada a do período anterior a pandemia. Contudo, a maioria avalia positivamente os esforços para a manutenção das atividades de ensino remoto tanto no que se refere às dinâmicas que estão sendo desenvolvidas quanto à aderência às atividades.

Palavras-chave: COVID-19. Ensino remoto. Isolamento social. Satisfação com a Vida.

\section{COMO CITAR ESTE ARTIGO}

ABNT: VIEIRA, K. M. et al.Vida de Estudante Durante a Pandemia: Isolamento Social, Ensino Remoto e Satisfação com a Vida. EaD em Foco, v. 10, n. 3, e1147, 2020.

https://doi.org/10.18264/eadf.v10i3.1147 


\title{
Student Life During Pandemic: Social Isolation, Remote Education and Life Satisfaction
}

\begin{abstract}
The COVID-19 pandemic hit many countries in 2020, including Brazil, which adopted several measures to combat the virus, thus interfering in the life of society, especially with the demand for social isolation. To maintain teaching activities, the Federal University of Santa Maria initiated the Special Home Exercises Regime, for face-to-face courses. This study investigated social isolation, the adoption of remote education and the change in satisfaction with the lives of these students. For that, an online survey was adopted, whose answers were analyzed with descriptive statistics, exploratory factor analysis and multiple linear regression. The results indicate that the majority of students are practicing isolation and leaving home only to purchase essential products. In this process of "staying at home" students perceive a drop in productivity, changes in mood and feelings of anguish and anxiety. Satisfaction with life today is lower when compared to the period before the pandemic. However, most of them positively evaluate the efforts to maintain remote teaching activities, both in terms of the dynamics that are being developed and in terms of adherence to activities.
\end{abstract}

Keywords: COVID-19. Remote teaching. Social isolation. Satisfaction with Life.

\section{Introdução}

O início do ano de 2020 foi marcado por um cenário delicado em diversas áreas devido à Pandemia de Coronavírus (COVID-19), que para seu enfrentamento está exigindo mudanças no comportamento da sociedade. No dia 30 de janeiro de 2020, a Organização Mundial da Saúde (OMS), declarou Emergência de Saúde Pública de Importância Internacional (GOV, 2020). No Brasil, a existência de transmissão comunitária da COVID-19, foi declarada em março pelo Ministério da Saúde (2020).

Diante disso, diversas ações foram adotadas para prevalecer o isolamento social, através de decretos Federais, Estaduais e Municipais, sendo o fechamento do comércio e escolas, a liberação de atividades apenas que sejam essenciais, consideradas indispensáveis ao atendimento das necessidades da população. No mundo todo, medidas similares foram tomadas pelos demais países.

O isolamento social, ou seja, a recomendação de "ficar em casa", adotada para frear a disseminação da COVID-19, impactou de diversas formas a vida dos brasileiros. Para Bittencourt (2020), o isolamento social é incômodo e exige paciência. São usuais situações de ansiedade, estresse e angústia. As pessoas que tendem a ser efusivas podem sofrer mais com o isolamento social e ansiar por encontros sem mais tardar.

Uma das consequências da necessidade de isolamento social é a restrição das atividades laborais e escolares. As escolas foram as primeiras a serem fechadas. As instituições de educação, independente do grau de ensino, viram-se obrigadas a buscar alternativas para manter pelo menos parte de suas atividades, a exemplo do Regime de Exercícios Domiciliares Especiais (REDE), que caracteriza o ensino remoto e inclui atividades síncronas e assíncronas entre professores e alunos. 
Neste cenário, os alunos, até então adaptados e acostumados ao ensino presencial, passaram a conviver com um duplo desafio: a necessidade de isolamento e o aprendizado baseado em atividades remotas, que ensejam maior autonomia. De acordo com Silveira et al (2020), o que as universidades estão utilizando caracteriza-se como ensino remoto, considerado uma medida emergencial para o momento atípico. O ensino remoto consiste na adaptação ao uso de recursos tecnológicos e ferramentas de tecnologia de informação, no entanto, sem alterar a metodologia das atividades presenciais, mantendo o projeto pedagógico do ensino presencial. Diante disso, as atividades foram adaptadas conforme necessidade, para possibilitar e facilitar a realização das aulas e encontros através das plataformas digitais disponíveis (ALVES, 2020). A modificação repentina na forma de realização das aulas pode criar déficits de qualidade dos cursos, pois não há como simplesmente transpor o que é feito presencialmente para as salas de aulas virtuais, uma vez que essa prática exige outras competências nas dimensões técnica, humana, político-econômica e diferentes conhecimentos (KONRATH, TAROUCO E BEHAR, 2009).

Este cenário pode trazer para a vida do estudante mudanças significativas, tanto do ponto de vista econômico quanto nos aspectos social e emocional, já que o equilíbrio das pessoas e até mesmo da sociedade como um todo pode ser afetado por situações emergenciais como esta, que deixam no seu lastro perdas humanas, materiais e mudanças situacionais extremamente traumáticas (SA, WERLANG E PARANHOS, 2008). Acerca das respostas comportamentais das pessoas diante da pandemia, Kok et al. (2010) afirmam que podem afetar e gerar consequências sociais. Tais consequências podem afetar diretamente a satisfação com a vida dos indivíduos, ou seja, a percepção positiva ou negativa diante das mudanças que ocorrem em sua vida (CAMPARA, VIEIRA E POTRICH, 2017).

Assim, este estudo avalia a percepção de estudantes universitários sobre o efeito do isolamento social, da mudança para o ensino remoto e a alteração na satisfação com a vida. Dentre as variáveis, a pesquisa propõe-se a investigar como os discentes se sentiram diante dessas mudanças, o quanto o isolamento social impactou em sua vida e qual a percepção destes sobre as condições do ensino remoto, tanto em relação a aproveitamento quanto em condições de estrutura. Por essas razões, pode-se considerar este estudo como inovador, pois além de buscar entender o impacto de um fenômeno recente, até o presente não foram encontrados outros estudos que se proponham a tal investigação.

O valor principal deste estudo é buscar a resposta do comportamento e a satisfação social frente às medidas de saúde pública necessárias para enfrentar e frear a pandemia. Entender esses efeitos pode auxiliar os diversos órgãos de gestão - tanto em nível de Governo Federal quanto a gestão de outras instituições - a buscar alternativas que considerem os aspectos psicossociais, visando a uma renovação e aprimoramento dos planos de contingência e uma futura agenda de medidas para conter os possíveis efeitos negativos tanto para o ensino quanto econômicos, sociais ou psicológicos da pandemia COVID-19.

\section{Método}

A Universidade Federal de Santa Maria (UFSM) conta com 254 cursos presenciais, nos quais estão ativos e regularmente vinculados um total de 27.200 alunos (UFSM, 2020). Para essa população e, considerando-se um erro amostral de 3,1\%, com 95\% de confiança, tem-se uma amostra de 965 alunos. A pesquisa foi aprovada pelo comitê de ética em pesquisa (CAAE: 30883020.4.1001.5346). O instrumento de coleta de dados foi disponibilizado de forma online através do link de acesso nos portais oficiais e através do sistema de questionários da Universidade e também em redes sociais. O questionário conta com questões de isolamento social (39) curso e instituição (05), ensino remoto (43), satisfação com a vida (02) e perfil (06). A parte inicial engloba as questões de isolamento social que visam identificar o comportamento diante do isolamento social e sentimentos relacionados ao isolamento social. Para obtenção das respostas, utilizou-se uma escala de grau de concordância (1- discordo totalmente, 2 - discordo em partes, 3 - indiferente, 4 - concordo em parte, 5 - concordo totalmente). 
No segundo bloco estão perguntas relacionadas ao curso e à instituição de ensino, em que fase do curso o aluno se encontra, se o mesmo é bolsista, dentre outras. O terceiro bloco refere-se ao ensino remoto diante do isolamento social, contendo questões como a opinião do mesmo sobre a decisão da universidade em aderir ao ensino remoto. Este bloco apresenta dois construtos: o primeiro, com 19 questões que medem o grau de concordância relacionado às disciplinas que o aluno está cursando; o outro,com 18 questões sobre adequação das disciplinas ao ensino remoto. Para a satisfação com a vida, foram feitas mais duas questões relacionadas a antes e depois da pandemia, com escala de satisfação composta por questão quantitativa de onze pontos (0 a 10). Por último, foi averiguado o perfil dos entrevistados, com gênero, idade, estado civil, renda mensal própria, ocupação e filhos.

A análise de dados ocorreu em duas fases: a estatística descritiva e a estatística multivariada. A primeira etapa se refere à estatística descritiva das variáveis com a finalidade de caracterizar a amostra e descrever o comportamento dos estudantes em relação a cada um dos fatores avaliados. Na segunda fase, foram aplicadas a análise fatorial e a análise de regressão múltipla. A fim de verificar se a análise fatorial é apropriada para a amostra, foram aplicados dois testes: o teste de esfericidade de Barlett e o teste de Kaiser-Meyer-Olkin (KMO). Para manutenção das variáveis na análise fatorial, utilizou-se o critério das comunalidades, sendo mantidas as variáveis com comunalidades maiores ou iguais a 0,5. Para a estimação das cargas fatoriais, usou-se o método dos componentes principais, e para definir o número de fatores, foram utilizados os critérios dos autovalores maiores que 1,0 e porcentagem da variância explicada. Como técnica de rotação, utilizou-se a rotação varimax normalizada. Para avaliar o nível de confiabilidade dos fatores gerados através da análise fatorial, usou-se o Alpha de Cronbach, sendo valores superior a 0,6 considerados aceitáveis (HAIR et al., 2009).

Finalizando as análises, o estudo se propôs a verificar o impacto dos fatores relativos ao isolamento social e ao ensino remoto na mudança na satisfação com a vida, através de uma análise de regressão múltipla. Assim, foi estimado um modelo de regressão linear pelo método dos mínimos quadrados ordinários. Para verificar a normalidade e homocedasticidade, foram aplicados os testes Kolmogorov Smirnov (KS) e Pesarán-Pesarán, respectivamente. Para análise da multicolineariedade entre as variáveis independentes, foi utilizado o fator de inflação da variância (FIV).

\section{Análise dos resultados}

A pesquisa online foi aplicada entre os dias 21 de março e 12 de abril de 2020; foram obtidos um total de 977 instrumentos válidos. Dentre os respondentes, a predominância é dos que se classificam como Mulher Cisgênera (61,6\%) e Homem Cisgênero (28,4\%). Quanto à idade, a média foi de 26,3 anos com desvio padrão de 8,6, destacando-se as faixas de 16 a 20 anos e 24 a 30 anos, com 27,9\% e 25,5\% respectivamente. Sobre a renda, $27,5 \%$ informaram não possuir renda própria, outros $25 \%$ possuem renda de até $R \$ 1.045,00$, e 19,5\% possuem renda entre $R \$ 1.045,01$ e $R \$ 2.090,00$. O estado civil predominante é o solteiro(a), representando 77,3\% da amostra. Quanto a filhos, 85,4\% informou não possuir e 8,5\% tem apenas um. A ocupação mais representativa é das pessoas que se dedicam somente aos estudos (42,1\%) ou recebem algum tipo de remuneração proveniente de atividades em bolsas de incentivo (21,3\%). Ainda sobre a ocupação, dentre os que marcaram a opção "Outros" (15,4\%), destacam-se os trabalhadores informais e desempregados(a) à procura de emprego.

A maioria se encontra em nível de graduação presencial (66,5\%), seguido dos respondentes em nível de mestrado (17,3\%). Para a opção "Outros", o principal citado foi o curso do nível técnico e especialização (2,5\%). Quanto à fase em que se encontra, a opção com mais respostas foi a que indica que o aluno está iniciando o curso agora (30,1\%), seguido do grupo que está com 10 a 30\% do curso concluído (18,1\%). Em relação à atuação em bolsas de pesquisa, ensino, extensão ou auxílio, 75,9\% dos respondentes não possuem bolsa remunerada. 
Dentre as orientações de isolamento social, a maioria dos alunos disse que está saindo de casa para aquisição de produtos essenciais (77,1\%) e 20,9\% declararam que estão isolados sem sair de casa. Já $16,1 \%$ afirmaram estar saindo de casa para trabalhar, e uma minoria diz sair para atividades físicas e de lazer (7,2\%) e para comprar de produtos não essenciais (1,9\%). A fim de identificar como está a rotina dos alunos de acordo com as orientações de isolamento social, a Tabela 1 contém graus de concordância e média de cada variável.

Tabela 1: Rotina dos discentes diante do isolamento social

\begin{tabular}{|c|c|c|c|c|c|c|}
\hline \multirow[b]{2}{*}{$\begin{array}{l}\text { Rotina diante do } \\
\text { Isolamento Social }\end{array}$} & \multirow[b]{2}{*}{ Média } & \multicolumn{5}{|c|}{ Percentuais } \\
\hline & & $\begin{array}{l}\text { Discordo } \\
\text { totalmente }\end{array}$ & $\begin{array}{l}\text { Discordo } \\
\text { parcialmen- } \\
\text { te }\end{array}$ & Indiferente & $\begin{array}{l}\text { Concordo } \\
\text { parcialmen- } \\
\text { te }\end{array}$ & $\begin{array}{l}\text { Concordo } \\
\text { totalmen- } \\
\text { te }\end{array}$ \\
\hline $\begin{array}{l}\text { Ficar em casa trouxe } \\
\text { grandes mudanças } \\
\text { na minha vida }\end{array}$ & 3,98 & 3,9 & 9,1 & 12,3 & 34,8 & 39,9 \\
\hline $\begin{array}{l}\text { Ficar em casa o } \\
\text { tempo todo me deixa } \\
\text { estressado }\end{array}$ & 3,73 & 8,6 & 13,4 & 8,7 & 34,6 & 34,7 \\
\hline $\begin{array}{l}\text { Acredito que o } \\
\text { isolamento social é } \\
\text { eficaz na contenção } \\
\text { da disseminação do } \\
\text { coronavírus }\end{array}$ & 4,77 & 1,7 & 1,2 & 0,8 & 10,5 & 85,7 \\
\hline $\begin{array}{l}\text { Estou confiante de } \\
\text { que o isolamento } \\
\text { social protege a mim } \\
\text { mesmo e a minha } \\
\text { família contra o coro- } \\
\text { navírus }\end{array}$ & 4,68 & 1,3 & 2,6 & 1,2 & 16,3 & 78,6 \\
\hline $\begin{array}{l}\text { Sinto que minha } \\
\text { produtividade caiu } \\
\text { devido ao isolamento } \\
\text { social }\end{array}$ & 3,9 & 8,4 & 11 & 7,9 & 27,6 & 45,1 \\
\hline $\begin{array}{l}\text { Tenho sentimentos } \\
\text { de depressão devido } \\
\text { ao isolamento social. }\end{array}$ & 3,10 & 22,5 & 12,7 & 17,4 & 27,2 & 20,2 \\
\hline $\begin{array}{l}\text { Tenho alteração de } \\
\text { humor devido ao } \\
\text { isolamento social. }\end{array}$ & 3,64 & 12,2 & 9,6 & 12,0 & 34,4 & 31,8 \\
\hline $\begin{array}{l}\text { Tenho sentimentos } \\
\text { de angústia devido ao } \\
\text { isolamento social. }\end{array}$ & 3,65 & 14,0 & 8,9 & 10,6 & 30,7 & 35,7 \\
\hline $\begin{array}{l}\text { Tenho alteração de } \\
\text { apetite devido ao } \\
\text { isolamento social. }\end{array}$ & 3,46 & 17,4 & 8,8 & 15,8 & 26,2 & 31,8 \\
\hline $\begin{array}{l}\text { Tenho ingerido álcool } \\
\text { numa frequência } \\
\text { maior devido ao iso- } \\
\text { lamento social. }\end{array}$ & 1,99 & 59,2 & 9,2 & 13,5 & 9,6 & 8,5 \\
\hline $\begin{array}{l}\text { Tenho sentimento de } \\
\text { ansiedade devido ao } \\
\text { isolamento social }\end{array}$ & 3,73 & 13,1 & 9,0 & 9,2 & 28,9 & 39,8 \\
\hline
\end{tabular}


Nota-se que há um elevado grau de concordância dos alunos com a eficácia do isolamento social na contenção da disseminação do coronavírus, e estão confiantes de que o isolamento social protege a si mesmo e a sua família contra o coronavírus. Essas duas concordâncias estão de acordo com as orientações do Ministério da Saúde (2020), que defende o isolamento social como essencial para evitar uma aceleração descontrolada da doença.

Sobre o sentimento de queda de produtividade dos alunos somam-se (72,7\%) os que concordam parcialmente e totalmente. A maioria discorda de que tenha aumentado o consumo de álcool, mas concorda ou concorda totalmente de que há alteração de apetite. Quanto aos efeitos psicológicos do isolamento, pode-se observar que grande parte da amostra indica que estão ocorrendo alterações de humor e sentimentos de angústia e ansiedade. Tais resultados vão ao encontro do estudo de Bittencourt (2020), que afirma que o isolamento social é incômodo e são usuais situações de ansiedade, estresse, angústia.

Quanto às práticas das medidas evitar bares, restaurantes e shoppings (95,7\%), usar máscara de proteção $(93,8 \%)$ e lavar frequentemente as mãos com água e sabão $(91,9 \%)$. Em relação ao comportamento de compras, $82,2 \%$ responderam que compram somente os itens necessários e 49,6\% fazem compras pela internet. Já em relação à ocupação, $(87,7 \%)$ apontam estar realizando atividades escolares a distância e $(58,2 \%)$ estão trabalhando em casa.

Neste sentido, Garcia e Duarte (2020) elencam Intervenções não Farmacológicas (INF) para o enfrentamento à epidemia da COVID-19, como higiene das mãos, a etiqueta respiratória e o distanciamento social. Dentre as INF apresentadas pelos autores, a maioria dos alunos da UFSM respondeu lavar frequentemente as mãos com água e sabão, usam a etiqueta da tosse (ao tossir e espirrar, usar o antebraço, caso não tenha lenço) e apontam manter a distância recomendada de outras pessoas. Quando questionados quanto ao número de dias em que acreditavam que o isolamento social ainda permaneceria, a resposta média foi de 69 dias, com limite inferior de 10 dias e máximo de 500 dias.

Após a análise da situação de isolamento social, buscou-se analisar a mudança na satisfação com a vida dos estudantes. Os estudantes atribuíram notas de zero (nada satisfeito) a dez (totalmente satisfeito) para a satisfação com a vida antes e desde o início da pandemia. A Figura 1 apresenta as distribuições de frequência antes da pandemia, desde o início da pandemia e a variação da satisfação.
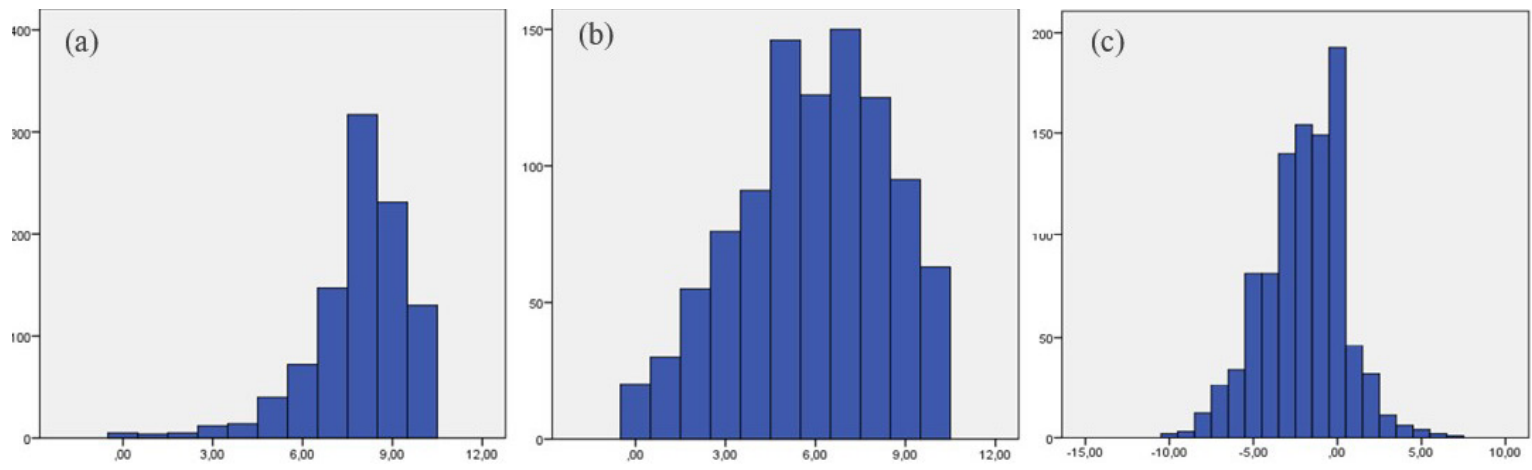

Figura 1: Grau de satisfação com a vida antes da pandemia (a) grau de satisfação com a vida neste momento (b) e variação entre estes (c)

Fonte: Dados da pesquisa (2020)

Para a Satisfação com a Vida antes da pandemia (a), o desvio padrão foi de 1,678 e a média das respostas foi de 7,86, podendo ser considerado um bom grau de satisfação geral com a vida, por tender mais ao 
nível "Muito satisfeito". Já para a satisfação com a vida no momento atual (b), as respostas apresentaram desvio padrão de 2,489 e média de 5,89, podendo ser considerado um grau intermediário, por tender mais ao nível "satisfeito". Para uma melhor avaliação da mudança, computou-se a diferença entre a avaliação desde o início da pandemia e antes da pandemia. A variação (c) mostra que, para a maioria, houve uma queda na satisfação com a vida, a qual foi em média de 2 pontos na escala.

Na etapa seguinte da pesquisa, buscou-se avaliar a percepção dos discentes quanto ao ensino remoto. A maior parte dos respondentes $(86,1 \%)$ afirmou que está tendo atividades nas disciplinas em que está matriculado e (66\%) considera adequada a decisão da instituição de ensino em permiti-las durante a suspensão das aulas presenciais. A Figura 2 mostra a quantidade de disciplinas em que o aluno está matriculado, em quantas está tendo atividade e sua satisfação com as atividades de ensino remoto.
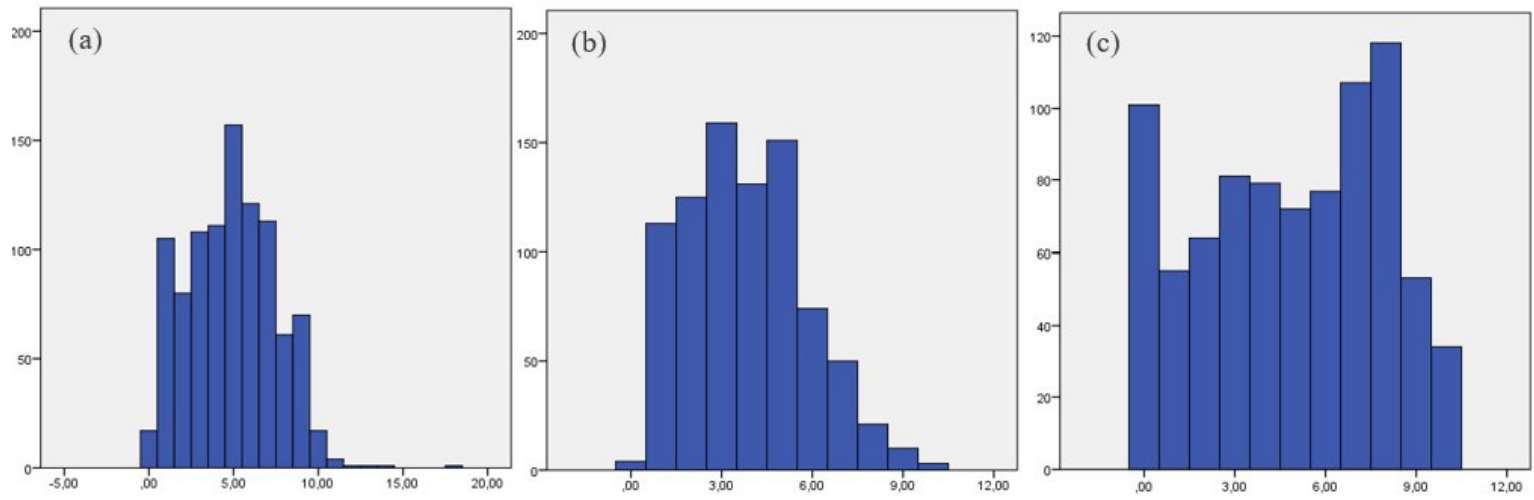

Figura 2: Quantidade de disciplinas em que estão matriculados (a), quantidade de disciplinas em que estão tendo atividades (b) e satisfação com as atividades de ensino remoto (c) Fonte: Dados da pesquisa (2020)

Os dados (a) mostram que os respondentes estão matriculados em média em 4,88 disciplinas (desvio-padrão 2,598). Alguns respondentes informaram “0 disciplinas" justificando terem trancado a matrícula no semestre. E, para a opção estão tendo atividades, a média é de 3,81 (desvio-padrão 1,982). Para a satisfação com as atividades (c), em uma escala de zero (nada satisfeito) a dez (totalmente satisfeito), a média de respostas foi de 4,84 (desvio-padrão 3,014), indicando insatisfação dos respondentes com as atividades.

Quando questionados sobre qual seria a decisão deles, caso tivessem a oportunidade de decidir sobre a implementação das atividades a distância, o maior percentual de respostas foi "Não haveria nenhuma atividade a distância e o semestre letivo seria cancelado, ou seja, no ano de 2020 seria possível cursar apenas um semestre letivo" com 26,3\% dos entrevistados. Outra parcela semelhante (23,8\%) considera que a utilização das atividades a distância deveria ficar a critério de cada docente, e a carga horária dada seria computada para o primeiro semestre de 2020 para as disciplinas que tiverem ensino a distância $(23,8 \%)$.

A adoção das atividades remotas na instituição diante do cenário pandêmico trouxe para a maioria dos discentes e docentes um método de ensino totalmente novo. Assim, para avaliar a percepção dos discentes quanto a esta mudança, utilizaram-se duas escalas: A primeira, denominada Dinâmica do Ensino Remoto, com escala Likert de 5 pontos, sendo 1 - Discordo Totalmente e 5 - Concordo Plenamente; A segunda dimensão, Aderência ao Ensino Remoto, com escala tipo Likert de 5 pontos, sendo 1 - Totalmente Inadequado e 5 - Totalmente Adequado. As Tabelas 2 e 3 apresentam os resultados de cada uma das dimensões. 
Tabela 2: Composição da dimensão Dinâmica do Ensino Remoto: Alpha de Cronbach, média e variância dos fatores e média e carga fatorial das variáveis

\begin{tabular}{|c|c|c|c|}
\hline Questão & Média & Carga & Variância \\
\hline Fator 1: Suporte dos professores (Alpha de Cronbach: 0,918) & 3,77 & - & \multirow{9}{*}{$45,88 \%$} \\
\hline $\begin{array}{l}\text { Quando tenho dificuldades, os professores mostram interesse } \\
\text { em resolvê-las. }\end{array}$ & 4,06 & 0,843 & \\
\hline Os professores demonstram uma atitude positiva. & 3,91 & 0,817 & \\
\hline $\begin{array}{l}\text { Os professores estão sensíveis em atender as necessidades do } \\
\text { aluno. }\end{array}$ & 3,94 & 0,812 & \\
\hline $\begin{array}{l}\text { O tempo dos professores, dedicado a resolução das dúvidas } \\
\text { dos alunos, é } 4 \text {. }\end{array}$ & 3,74 & 0,746 & \\
\hline $\begin{array}{l}\text { O professor responde prontamente às minhas consultas/dúvi- } \\
\text { das. }\end{array}$ & 3,78 & 0,740 & \\
\hline $\begin{array}{l}\text { As respostas fornecidas pelo professor às dúvidas/questões dos } \\
\text { alunos relativas ao conteúdo da disciplina são adequadas. }\end{array}$ & 3,82 & 0,701 & \\
\hline Os materiais didáticos são atualizados e de boa qualidade. & 3,61 & 0,646 & \\
\hline Fico à vontade para fazer perguntas aos professores & 3,32 & 0,499 & \\
\hline $\begin{array}{l}\text { Fator 2: Adequação do Aluno às Atividades Remotas (Alpha } \\
\text { de Cronbach 0,861) }\end{array}$ & 2,79 & - & \multirow{6}{*}{$10,82 \%$} \\
\hline $\begin{array}{l}\text { Estou administrando adequadamente o tempo para me dedicar } \\
\text { aos estudos. }\end{array}$ & 2,51 & 0,810 & \\
\hline $\begin{array}{l}\text { A minha habilidade em estudar sozinho está me ajudando a } \\
\text { desenvolver as atividades. }\end{array}$ & 2,81 & 0,780 & \\
\hline Estou motivado para a realização das atividades das disciplinas. & 2,45 & 0,771 & \\
\hline As disciplinas estão atendendo as minhas expectativas. & 2,77 & 0,591 & \\
\hline $\begin{array}{l}\text { A minha habilidade em utilizar os recursos tecnológicos do cur- } \\
\text { so (ex.: internet, e-mail, fóruns, ferramentas de áudio e vídeo, } \\
\text { entre outros) está me ajudando a desenvolver as atividades. }\end{array}$ & 3,43 & 0,590 & \\
\hline Fator 3: Domínio da Tecnologia (Alpha de Cronbach 0,808) & 3,86 & - & \multirow{4}{*}{$6,35 \%$} \\
\hline $\begin{array}{l}\text { A infraestrutura (ex.: computador, internet, entre outros) que } \\
\text { eu disponho para estudar a distância é adequada. }\end{array}$ & 3,87 & 0,790 & \\
\hline $\begin{array}{l}\text { Consigo utilizar adequadamente as ferramentas do ambiente } \\
\text { virtual de aprendizagem (ex.: fórum, chat, mensagens, entre } \\
\text { outros) durante as disciplinas. }\end{array}$ & 3,69 & 0,675 & \\
\hline $\begin{array}{l}\text { Tenho fácil acesso (e-mail, chats, fóruns, etc.) aos professores, a } \\
\text { fim de me auxiliarem nas minhas dúvidas. }\end{array}$ & 4,03 & 0,628 & \\
\hline
\end{tabular}

Fonte: Dados da pesquisa (2020)

Na dimensão Dinâmica do Ensino Remoto, para atender o critério de comunalidade, foi excluída a variável: "Nas disciplinas foram apresentados os conteúdos programáticos" (comunalidade 0,419). A medida KMO apresentou o valor de 0,935, o teste de esfericidade de Bartlett foi significativo, confirmando a fatorabilidade dos dados. Quanto à variância, verifica-se que os quatro fatores que apresentaram autovalores superiores a um, em conjunto, explicam 63,05\% de toda a variância. Destaca-se que três deles apresentaram confiabilidade satisfatória, conforme o Alpha de Cronbach, tendo valores de 0,918, 0,861 e 0,808, e o quarto fator "Autonomia do Aluno" (Alpha de Cronbach 0,589) foi excluído da análise, pois, segundo Hair et. al (2009), em análise exploratória, o Alpha de Cronbach deve possuir um valor superior a 0,6 para que o fator tenha consistência interna. 
O fator Suporte dos Professores apresentou-se como o mais relevante para a formação da percepção dos alunos e corresponde às variáveis que avaliam a qualidade dos materiais disponibilizados, o interesse e a atenção dos professores com os alunos que precisam de suporte para a realização das atividades propostas. A média de 3,77 para esse fator sugere um elevado grau de concordância com a importância do papel do professor nesse contexto, da mesma forma em que as variáveis que destacam a participação do professor nesse processo possuem as maiores as cargas fatoriais. Tais resultados vão ao encontro de estudos como o de Lott et al. (2018), que indica o suporte à aprendizagem como um dos principais determinantes da permanência do discente em cursos a distância.

O fator Adequação do Aluno às Atividades Remotas, composto pelas variáveis que medem os esforços dos alunos a fim de se adaptarem ao ensino remoto, atingiu o segundo maior nível de variância explicada (10,82\%), porém com uma média de 2,79, indicando um nível de indiferença com a adaptação à modalidade de ensino, destacando-se a baixa média $(2,45)$ da variável "Estou motivado para a realização das atividades da disciplina". Observa-se que a adaptação ao sistema de ensino em REDE, não tem sido uma tarefa fácil, pois exige do aluno autonomia, automotivação e autodisciplina (Farias e Dias, 2010) - fatores estes que podem ser difíceis de serem mantidos em um cenário pandêmico que pode levar a efeitos psicológicos decorrentes do isolamento social.

Diferentemente do anterior, o fator Domínio das Tecnologias apresentou uma média elevada de concordância $(3,86)$, entendendo-se que a utilização das tecnologias de informação não representa dificuldades aos alunos respondentes. Desse fator, destaca-se a média elevada de concordância $(4,03)$ para a variável "Tenho fácil acesso (e-mail, chats, fóruns, etc.) aos professores, a fim de me auxiliarem nas minhas dúvidas", assinalando a facilidade de interação entre docentes e discentes. Observa-se que a utilização do sistema Moodle como instrumento auxiliar no ensino presencial propiciou que na mudança para o ensino em Rede o aluno já tivesse, pelo menos, um domínio básico de uma das tecnologias mais utilizadas pelos docentes.

A partir dos resultados verificados para a dimensão Dinâmica do Ensino Remoto, considerando-se que duas médias, de um total de três fatores analisados, foram próximas ao valor 4, numa escala que varia de 1 a 5, entende-se que a maior parte dos respondentes concordam com as afirmações que sugerem a disponibilidade de recursos e competências de docentes e discentes para o Ensino Remoto.

Na dimensão Aderência ao Ensino Remoto, a medida KMO apresentou o valor de 0,952, o teste de esfericidade de Bartlett o valor de 7199,758 (Sig 0,000; GL 136). Confirmada a fatorabilidade dos dados, elaborou-se a Tabela 3 para apresentar os resultados.

Tabela 3: Composição da Dimensão Aderência ao Ensino Remoto: Alpha de Cronbach, média e variância dos fatores e média e carga fatorial das variáveis

\begin{tabular}{|c|c|c|c|}
\hline Questão & Média & Carga & Variância \\
\hline $\begin{array}{l}\text { Fator 1: Adaptação dos Recursos Didáticos (Alpha de Cronbach } \\
0,949 \text { ) }\end{array}$ & 3,44 & - & \multirow{6}{*}{$52,63 \%$} \\
\hline Condução das aulas online. & 3,36 & 0,812 & \\
\hline $\begin{array}{l}\text { As interações de aprendizagem (entre os alunos, entre alunos e pro- } \\
\text { fessor) nas disciplinas. }\end{array}$ & 3,39 & 0,776 & \\
\hline $\begin{array}{l}\text { A qualidade do feedback/orientações fornecidos pelo professor em } \\
\text { relação às minhas participações. }\end{array}$ & 3,38 & 0,758 & \\
\hline As videoaulas disponibilizadas. & 3,46 & 0,741 & \\
\hline $\begin{array}{l}\text { A disponibilização de ferramentas (ex: fóruns, chat, mensagens, } \\
\text { entre outros) no ambiente virtual de aprendizagem para a interação } \\
\text { dos alunos e professor. }\end{array}$ & 3,64 & 0,737 & \\
\hline
\end{tabular}




\begin{tabular}{|c|c|c|c|}
\hline A adequação das disciplinas às minhas expectativas. & 2,81 & 0,727 & \multirow{9}{*}{$52,63 \%$} \\
\hline As avaliações das disciplinas. & 3,23 & 0,711 & \\
\hline $\begin{array}{l}\text { A prontidão (rapidez) de resposta do professor às minhas consultas/ } \\
\text { dúvidas. }\end{array}$ & 3,59 & 0,707 & \\
\hline O conteúdo das mensagens trocadas. & 3,76 & 0,704 & \\
\hline A duração (tempo) das atividades das disciplinas. & 3,39 & 0,653 & \\
\hline A qualidade dos materiais didáticos das disciplinas. & 3,63 & 0,642 & \\
\hline O acesso ao material didático utilizado nas disciplinas. & 3,69 & 0,642 & \\
\hline $\begin{array}{l}\text { A quantidade de atividades propostas em relação à carga horária das } \\
\text { disciplinas. }\end{array}$ & 3,18 & 0,621 & \\
\hline O acesso ao ambiente virtual de aprendizagem das disciplinas. & 3,70 & 0,578 & \\
\hline Fator 2: Adaptação do Aluno (Alpha de Cronbach 0,675 ) & 3,61 & - & \multirow{4}{*}{$6,55 \%$} \\
\hline As condições do ambiente de estudo em casa. & 3,30 & 0,741 & \\
\hline A minha familiaridade com o uso do computador. & 4,14 & 0,739 & \\
\hline O meu tempo disponível para a realização das disciplinas. & 3,38 & 0,693 & \\
\hline
\end{tabular}

Fonte: Dados da pesquisa (2020)

Todas as variáveis apresentaram cargas fatoriais satisfatórias, e os dois fatores que apresentaram autovalores superiores a um, em conjunto, explicam 59,18\% de toda a variância, o que os caracteriza também como satisfatórios. Destaca-se também a excelente confiabilidade de ambos, indicada pelo Alpha de Cronbach.

Dentre os fatores, a Adaptação dos Recursos Didáticos corresponde às variáveis que medem a qualidade dos recursos didáticos e a disponibilidade das tecnologias utilizadas pelos docentes e disponíveis aos discentes. A partir da média $(3,44)$, entende-se que os respondentes consideram os recursos como adequados ao Ensino Remoto.

O segundo fator, Adaptação do Aluno, avalia as condições de adaptação do aluno com a modalidade de ensino a distância. Com média 3,61, esse fator sugere que grande parte dos respondentes considera como adequada a adaptação para o Ensino Remoto. As condições do ambiente de estudo em casa foi a variável com menor média neste fator, destacando que, para alguns discentes, pode estar havendo dificuldades com o acesso à internet, à disponibilidade de um equipamento apropriado ou a um local adequado para estudo. Num contexto pandêmico, com a determinação de distanciamento social e o incentivo para "ficar em casa", o ambiente familiar passa necessariamente por grandes mudanças, podendo haver maior circulação de pessoas, maior demanda de uso de internet e necessidade de compartilhamento de equipamentos de informática, o que pode dificultar a adaptação do aluno ao ensino em rede.

Com o objetivo de conhecer a percepção dos discentes sobre a adoção do Isolamento Social, utilizou-se uma escala denominada Percepção do Isolamento Social. A Tabela 4 apresenta a fatorial da escala. 
Tabela 4: Percepção do Isolamento Social: Alpha de Cronbach, média e variância dos fatores e média e carga fatorial das variáveis

\begin{tabular}{|c|c|c|c|}
\hline Variáveis & Média & Carga & Variância \\
\hline $\begin{array}{l}\text { Fator 1: Sentimentos durante o Isolamento Social (Alpha de } \\
\text { Cronbach: } 0,913 \text { ) }\end{array}$ & 3,57 & - & \multirow{6}{*}{$53,55 \%$} \\
\hline Tenho sentimentos de angústia devido ao isolamento social. & 3,65 & 0,900 & \\
\hline Tenho alteração de humor devido ao isolamento social. & 3,64 & 0,889 & \\
\hline Tenho sentimento de ansiedade devido ao isolamento social. & 3,73 & 0,875 & \\
\hline Tenho sentimentos de depressão devido ao isolamento social. & 3,10 & 0,856 & \\
\hline "Ficar em casa" o tempo todo me deixa estressado. & 3,73 & 0,778 & \\
\hline $\begin{array}{l}\text { Fator 2: Eficácia do Isolamento Social (Alpha de Cronbach: } \\
0,831)\end{array}$ & 4,73 & - & \multirow{3}{*}{$24,00 \%$} \\
\hline $\begin{array}{l}\text { Estou confiante de que o isolamento social protege a mim mes- } \\
\text { mo e à minha família contra o coronavírus. }\end{array}$ & 4,68 & 0,924 & \\
\hline $\begin{array}{l}\text { Acredito que o isolamento social é eficaz na contenção da disse- } \\
\text { minação do coronavírus. }\end{array}$ & 4,77 & 0,922 & \\
\hline
\end{tabular}

Fonte: Dados da pesquisa (2020)

Para atender o critério de comunalidades, foram excluídas quatro variáveis: A medida KMO apresentou o valor de 0,8245 , o teste de esfericidade de Bartlett foi significativo, confirmando a fatorabilidade dos dados.

O primeiro fator, denominado Sentimentos durante o Isolamento Social, corresponde a 53,55\% da variância explicada total e é composto por variáveis que visam averiguar as possíveis mudanças e oscilações emocionais e comportamentais dos discentes durante o isolamento social. A média do fator é de 3,57, o que sugere um elevado grau de concordância quanto a alterações negativas nos sentimentos, emoções e comportamentos dos respondentes. Tais resultados vão ao encontro dos estudos que indicam que a pandemia da COVID-19 tem causado efeitos psicológicos, como a ansiedade, depressão e diferentes níveis de estresse (Cao et al., 2020, Qiu et al., 2020, Wang et al., 2020).

O segundo fator, Eficácia do Isolamento Social, é formado por apenas duas variáveis e apresenta média de 4,73, mostrando elevado grau de concordância dos respondentes quanto à eficácia do Isolamento Social como medida de combate ao coronavírus. Tal percepção é fundamental para que as medidas adotadas contribuam efetivamente para o controle da doença, já que o distanciamento é a principal medida de combate à disseminação da COVID-19.

A influência das variáveis estudadas na Satisfação com a Vida foi verificada através da análise de regressão linear, onde a Satisfação com a Vida na pandemia representa a variável dependente, e os sete fatores encontrados através das análises fatoriais, bem como as variáveis idade e as cinco variáveis binárias, representam as variáveis independentes. As variáveis binárias foram: Dummy gênero (1- mulher e 0 homem), Dummy renda (1 significa inexistência de renda e 0 existência); Dummy estado civil (0 representa outros e 1 casado(a)), Dummy filhos (0 sem filhos e 1 possui filhos), Dummy ocupação (0 outras ocupações e 1 somente estudante). Para a estimação do modelo de regressão linear, utilizou-se os Mínimos Quadrados Ordinários (MQO); os parâmetros estimados são apresentados na Tabela 5. 
Tabela 5: Valores e significância dos coeficientes do modelo de regressão estimado para a Satisfação com a Vida na pandemia.

\begin{tabular}{|c|c|c|c|c|}
\hline \multirow{2}{*}{ Modelo } & \multirow{2}{*}{ Coeficientes } & \multicolumn{2}{|c|}{ Teste $\mathrm{t}$} & \multirow{2}{*}{ VIF } \\
\hline & & $T$ & Sig. & \\
\hline Idade & $-0,006$ & $-0,147$ & 0,883 & 2,316 \\
\hline Fator 01 Sentimentos no Isolamento & $-0,451$ & $-14,237$ & 0,000 & 1,291 \\
\hline Fator 02 Eficácia no Isolamento & 0,087 & 3,036 & 0,002 & 1,056 \\
\hline Fator 03 Suporte dos Professores & $-0,008$ & $-0,176$ & 0,860 & 2,933 \\
\hline $\begin{array}{l}\text { Fator } 04 \text { Adaptação às atividades de Ensino } \\
\text { Remoto }\end{array}$ & 0,222 & 4,939 & 0,000 & 2,591 \\
\hline Fator 05 Domínio da Tecnologia & 0,100 & 2,250 & 0,025 & 2,519 \\
\hline Fator 06 Adaptação dos Recursos Didáticos & 0,008 & 0,158 & 0,874 & 3,652 \\
\hline Fator 07 Adaptação do Aluno & $-0,019$ & $-0,440$ & 0,660 & 2,406 \\
\hline Dummy Gênero & 0,073 & 2,554 & 0,011 & 1,041 \\
\hline Dummy Renda & $-0,061$ & $-1,872$ & 0,062 & 1,346 \\
\hline Dummy Estado Civil & 0,105 & 2,992 & 0,003 & 1,569 \\
\hline Dummy Filhos & 0,013 & 0,320 & 0,749 & 2,054 \\
\hline Dummy Ocupação & 0,006 & 0,184 & 0,854 & 1,554 \\
\hline
\end{tabular}

Fonte: Dados da pesquisa (2020)

O resultado apresenta o $\mathrm{R}^{2}$ ajustado de 0,414, ou seja, as variáveis independentes explicam 41,4\% da variação na satisfação com a vida. Quanto aos índices VIF, todos ficaram próximos de 1, confirmando a ausência de multicolinearidade. O teste KS (valor 0,479 e Sig. 0,976) indica uma distribuição normal nos resíduos e o teste Pesarán-Pesarán indicou a homocedasticidade.

Seis variáveis independentes exercem influência na Satisfação com a Vida. As variáveis eficácia no isolamento, adaptação as atividades de ensino remoto, domínio da tecnologia e as Dummy gênero e estado civil exercem influência positiva. Já a variável sentimento no isolamento possui sentido inverso, influenciando negativamente na satisfação com a vida. O gênero feminino e as pessoas casadas possuem maior satisfação quando comparadas às do gênero masculino e solteiras. Comin et al. (2016) colaboram apontando em seu estudo que as pessoas casadas tendem a responder com maior frequência emoções positivas e de bem-estar.

A análise da regressão comprovou a influência positiva da percepção de eficácia do isolamento social na satisfação com a vida. Adaptação as atividades de ensino remoto e domínio da tecnologia também contribuíram positivamente na satisfação com a vida dos alunos. Tais resultados vão ao encontro de Bresciani e Conto (2012), os quais argumentam que as tecnologias, de maneira geral, auxiliam na evolução do homem e atuam como recurso para promover o bem-estar (físico e mental) do usuário.

O fator sentimento no isolamento foi o que apresentou o maior coeficiente, indicando sua importância para a satisfação com a vida. A influência negativa dos sentimentos no isolamento vai ao encontro de estudos que afirmam que os indivíduos que aderem ao isolamento social estão mais vulneráveis a manifestar transtornos de saúde mental, devido à privação e contenção social, aparecendo sintomas de sofrimento psíquico, em especial, relacionado ao estresse, ansiedade e depressão. Destaca-se ainda que as características sociodemográficas, como gênero, filhos, ocupação e os fatores suporte dos professores, adaptação dos recursos didáticos, adaptação do aluno, não foram significativas. 


\section{Considerações Finais}

A pandemia de COVID-19 afetou a vida de muitas pessoas no mundo todo, especialmente pela adoção de medidas não farmacológicas, a fim de controlar e reduzir o contágio da doença, já que não existe ainda vacina. Em decorrência dessas medidas, as escolas foram umas das primeiras a serem fechadas. Segundo dados do MEC (Brasil, 2020), há no Brasil, atualmente, 2,36 milhões de pessoas ligadas à rede federal de ensino, das quais 1,94 milhões estão com as atividades suspensas. Das 69 universidades federais, 57 estão com as atividades suspensas, afetando a rotina de 934.077 alunos. Dentre as que mantiveram atividades, algumas adotaram o Regime de Exercícios Domiciliares Especiais (REDE), que consiste na execução das atividades através do ensino remoto.

Este estudo teve por objetivo analisar a vida dos estudantes durante a pandemia, especialmente quanto ao isolamento social, às atividades remotas e à satisfação com a vida. Os resultados indicaram que a maioria dos alunos compreendeu a importância de atender as orientações dos órgãos de saúde e indicou que saem de casa somente para aquisição de produtos essenciais. Também ficou evidente que percebem o isolamento social como eficaz na contenção da disseminação do coronavírus e acreditam que estão se protegendo a si mesmos e a seus familiares. Percebeu-se uma redução nos níveis de Satisfação com a Vida desde o início da pandemia em aproximadamente 2 pontos, quando se compara os resultados obtidos ao período anterior à pandemia, o que vai ao encontro das observações de Nogueira (2001), que apresenta a importância da interação como forma de dar sentido às experiências e oferecer apoio, importantes elementos no processo de adaptação a novas rotinas.

Os resultados sugerem também que existem oportunidades de melhoria no que tange às atividades que são elaboradas e apresentadas aos alunos no formato de ensino remoto. Essa sinalização corrobora com as afirmações apresentadas sobre a complexidade do processo de mudança de aulas presenciais para aulas conduzidas remotamente, pois não basta fazer uso de boas ferramentas tecnológicas, como as plataformas denominadas de Ambientes Virtuais de Ensino e Aprendizagem (AVEA). Nesse formato, há a necessidade de um modelo mental diferente, tanto de alunos quanto de professores, pois o processo exige ainda mais do aluno, que precisa dedicar, muitas vezes, um tempo ainda maior para acessar os materiais e estudar, geralmente, sozinho. Observa-se que, na modalidade de aulas presenciais, há uma interação maior entre os alunos e entre alunos e professores, que é maior em sala de aula, seja pela proximidade ou pelo ambiente propício ao diálogo, quando esse é criado pelos participantes. A maior parte dos respondentes $(86,1 \%)$ afirmou que está recebendo atividades das disciplinas e uma parcela expressiva deles concorda com a proposta de ensino remoto durante o período da pandemia. Nestas atividades, a percepção dos alunos é de que o suporte dos professores possui elevada importância no processo, posicionamento que não surpreende, pois muitos fatores são relevantes e determinantes para o ensino remoto promova êxito em relação aos seus objetivos.

A passagem abrupta de um estilo de vida com amplo deslocamento e convívio social nos campi e salas de aulas da universidade para uma situação de isolamento social e ampla mudança na rotina de estudos traz consigo também desafios emocionais, os quais interferem diretamente na satisfação com a vida. A adoção do ensino remoto, mantendo a interação entre alunos e professores, foi uma opção, até então, da minoria das universidades públicas. No caso da UFSM, apesar de trazer alguns desafios, parece estar contribuindo para manter diversos aspectos da Satisfação com a Vida. Por fim, verificou-se que, na percepção dos respondentes, há uma influência positiva do isolamento social na satisfação, pois confiam na eficácia da medida - o que pode gerar a sensação de segurança. Evidenciou-se também que os fatores associados aos problemas psicológicos, como ansiedade, estresse e depressão oriundos da pandemia, interferem negativamente na Satisfação com a Vida. No entanto, de certa forma, o impacto foi amenizado devido à capacidade de adaptação às atividades de ensino remoto e domínio da tecnologia, característica fortemente presente nos estudantes.

Apesar dos esforços para coleta de dados em um período pandêmico, uma das limitações dessa pes- 
quisa é a possibilidade de viés amostral. Pesquisas online estão sujeitas a alguns vieses e, neste caso, o principal é o acesso à internet, já que, apesar de a pesquisa ter sido enviada pelo sistema da instituição a todos os discentes regularmente matriculados, alunos sem acesso à internet podem não ter tido a oportunidade de participar.

\section{Referências Bibliográficas}

ALVES, L.. Educação remota: entre a ilusão e a realidade. Interfaces Científicas-Educação, v. 8, n. 3, p. 348-365, 2020.

BITTENCOURT, R. N. Pandemia, isolamento social e colapso global. Revista Espaço Acadêmico, v. 19, n. 221, p. 168-178, 2020. ISSN 1519.6186

BRASIL. Ministério da Educação. CORONAVíRUS: Monitoramento nas instituições de ensino. Brasília, 2020. Disponível em:<http://portal.mec.gov.br/coronavírus/>. Acesso em: 17 de mai. 2020.

BRESCIANI, T. A.; CONTO, S. M. de. O impacto da tecnologia Nintendo ${ }^{\circ}$ Wii no tratamento fisioterapêutico e na satisfação de pacientes em uma clínica do Vale do Taquari. Revista destaques acadêmicos, vol. 4, n. 1, 2012.

CAMPARA, J. P.; VIEIRA, K. M.; POTRICH, A. C. G.. Satisfação geral com a vida e bem-estar financeiro: revelando as percepções dos beneficiários do Programa Bolsa Família. RAP: Revista Brasileira de Administração Pública, v. 51, n. 2, 2017.

COMIN, F. S. Fatores associados ao Bem-Estar Subjetivo em pessoas casadas e solteiras. Estudos de Psicologia. Campinas, 2016.

CAO, W. et al. The psychological impact of the COVID-19 epidemic on college students in China. Psychiatry research, 112934, 2020.

FARIAS, F. R.; DIAS, M. J.. Os desafios entre o ensino presencial e o ensino a distância: uma questão de cultura digital e de formação do educador. EaD em Foco-Revista Científica em Educação a Distância. v.1, n.1, 2010.

GARCIA, L. P.; DUARTE E. Intervenções não farmacológicas para o enfrentamento à epidemia da COVID-19 no Brasil. Epidemiologia e Serviços de Saúde. 2020.

GOVERNO FEDERAL. Transparência: Portarias publicadas sobre COVID-19. 10 DE ABR. 2020 Disponível em: <https://portalarquivos.saude.gov.br/images/pdf/2020/April/03/Portarias-publicadas-sobre-COVID.pdf> Acessado em 16 de abr. 2020.

HAIR, J. F. et al. Fundamentos de Métodos de Pesquisa em Administração. Porto Alegre: Bookman, 2009.

KOK, G. et al. Behavioural intentions in response to an influenza pandemic. BMC Public Health, v. 10, n. 1, p. 174, 2010. https://doi.org/10.1186/1471-2458-10-174

KONRATH, M. L. P.; TAROUCO, L. M. R.; BEHAR, P. A.. Competências: desafios para alunos, tutores e professores da EaD. RENOTE-Revista Novas Tecnologias na Educação, v. 7, n. 1, 2009. https://doi. org/10.22456/1679-1916.13912

LOTT, A. C. O et al. Persistência e Evasão na Educação a Distância: Examinando Fatores Explicativos. Revista Eletrônica de Ciência Administrativa, s. I., v. 17, n. 2, p. 149-171, 2018.

MINISTÉRIO DA SAÚDE. Ministério da Saúde declara transmissão comunitária nacional. 20 de março de 2020. Disponível em <https://www.saude.gov.br/noticias/agencia-saude/46568-ministerio-da-saude-declara-transmissao-comunitaria-nacional>. Acessado em 17 de abr. de 2020. 
NOGUEIRA, E. J.. Rede de relações sociais: um estudo transversal com homens e mulheres pertencentes a três grupos etários. Tese (Doutorado em Educação). Campinas, SP: Faculdade de Educação: UNICAMP, 2001.

QIU, J. et al.. A nationwide survey of psychological distress among Chinese people in the COVID-19 epidemic: implications and policy recommendations. General Psychiatry, v.33, n.2, e100213, 2020.

SÁ, S. D.; WERLANG, B. S. G.; PARANHOS, M. E.. Intervenção em crise. Revista Brasileira de Terapias Cognitivas, Rio de Janeiro, v. 4, n. 1, jun. 2008.

SILVEIRA, S. R. et al. O Papel dos licenciados em computação no apoio ao ensino remoto em tempos de isolamento social devido à pandemia da COVID-19. 2020. Série Educar-Volume 40, Prática Docente, p. 35.

UNIVERSIDADE FEDERAL DE SANTA MARIA UFSM em números. Disponível em:<https://portal.ufsm.br/ ufsm-em-numeros/publico/painel.html?categoria=102>. Acesso em: 28 de abr, 2020.

WANG, C. et al. Immediate Psychological Responses and Associated Factors during the Initial Stage of the 2019 Coronavirus Disease (COVID-19) Epidemic among the General Population in China. Int. J. Environ. Res. Public Health, 17, 1729, 2020. 